\title{
The Relationship between Human Resource Management and Employee Counterproductive Work Behavior in New Ventures
}

\author{
Hongying Li* \\ Yatai School of Business Administration \\ Jilin University of Finance and Economics \\ Changchun, China \\ 87944255@qq.com
}

\author{
Yanling Cao \\ Yatai School of Business Administration \\ Jilin University of Finance and Economics \\ Changchun, China \\ caoyanling76@163.com
}

\begin{abstract}
Drawing on the social exchange theory, this study investigated the influence of human resource management on counterproductive work behavior in new ventures and verified the moderating effect of leader-member exchange and the mediating effect of employee satisfaction. With a sample of 526 employees, results from regression analysis indicate that: (1) human resource management has a significant negative impact on employee counterproductive work behavior. (2) employee satisfaction has a mediating effect between human resource management and employee counterproductive work behavior. (3) leader-member exchange strengthens the negative influence of human resource management on counterproductive work behavior. And then theoretical implications and practical implications were discussed.
\end{abstract}

Keywords-human resource management; counterproductive work behavior; leader-member exchange; employee satisfaction

\section{INTRODUCTION}

According to the Global Entrepreneurship Monitor (GEM) report, new ventures refer to businesses that have been established for less than 42 months. In the context of mass entrepreneurship and innovation, the quality of entrepreneurial activities in China has been greatly improved, but there are also many new ventures failing. How to effectively motivate and manage employees' performance in new ventures has become an important issue affecting the development of new ventures.

Counterproductive work behavior (CWB) refers to the spontaneous behavior of employees that intentionally damages the interests of the organization or its members (Marcus, Taylor, Hastings, et al., 2016) [1]. CWB is widespread in new ventures and has an increasingly negative impact on the organization. Therefore, it has become a hot issue of academic concern. In order to reduce the occurrence of this kind of behavior, scholars from different research perspectives explore its causes and impact mechanism, and then adopt appropriate strategies to reduce or suppress the occurrence of such

The research was supported by the Youth Fund for Humanities and Social Sciences Research from Ministry of Education of the PRC (project number: 18YJC630067), Social Science Foundation Project of Jilin Province in 2019 (project number: 2019C47), The project sponsored by Education Department of Jilin Province (project number: JJKH20190751SK), Scientific Research Project of Jilin University of Finance and Economics (project number: 2017B29). behavior.

Therefore, this paper starts from the perspective of human resources management to explore its impact on employees' counterproductive work behavior and discusses the mediating effect of employee satisfaction as well as the moderating role of leader-member exchange through empirical research. Finally, this study provides some suggestions for employee management in new ventures.

\section{THEORY AND HYPOTHESES}

\section{A. Human Resource Management in New Ventures and Counterproductive work behavior}

Social exchange theory can effectively explain the impact of human resource management on employee counterproductive work behavior. Employees and enterprises take reciprocity as the core principle and establish a social exchange relationship. When employees benefit from the enterprise and human resource management (HRM), based on the principle of reciprocity, employees would be motivated and encouraged to improve their positive behavior and to decline their negative behavior. Through human resources management, enterprises have formulated an attractive salary and incentive system for employees to encourage them to work more effectively in organization. At the same time, enterprises provide opportunities for employees to participate in training and decision-making, and use this intrinsic compensation mechanism to motivate employees. Employees and enterprises have formed a benign exchange mode. Enterprises provide human resources practice for employees, while employees return positive behavior feedback and reduce counterproductive work behavior (CWB).

Many researchers had investigated the relationship between HRM and employee CWB. Wang, Zhang \& Fan (2018) found that high-performance work system was negatively related to CWB and psychological contract violation, and psychological contract violation mediated the relationship between high-performance work system and CWB [2]. Subsequent research also found that human resource management was negatively related to CWB, and positive emotions mediated the relationship between them (Wang, Zhang \& Jia, 2019) [3]. Therefore, it was predicted that: 
H1: HRM will negatively associate with employee counterproductive work behavior.

\section{B. The moderating role of Employee Satisfaction}

Employee satisfaction is often related to work environment, compensation, training, corporate culture and promotion opportunity. Through effective human resources management, employees can be provided with a fair and competitive salary system. At the same time, it also provides employees with knowledge and skills training, promotion channels and so on, which can meet the staff's spiritual and material needs, so as to improve employee satisfaction. Heffernan \& Dundon (2016) [4] demonstrated that HRM could increase employee satisfaction, and employee perceptions of the fairness had the mediating influence. Huang, Ma \& Meng (2018) [5] showed that HRM are positively related to employees' positive mood and job satisfaction, and job satisfaction and positive mood lead to high employee engagement. Therefore, the following hypothesis is put forward.

H2: Human resource management of new ventures has a significant positive impact on employee satisfaction.

Human Resource Management in New Ventures will affect employee satisfaction and further has influence on employee counterproductive work behavior, which reflects the logic of stimulus-attitude-behavior. When the organization implements high-quality human resource management, employees and employers establish high-quality exchange relationships. Therefore, employees get high satisfaction, and reduce counterproductive work behavior.

Previous research has also proved that positive emotions, such as happiness, satisfaction and pride, mediate the relationship between human resource management and counterproductive work behavior (Wang, Zhang \& Jia, 2019) ${ }^{[3]}$. Therefore, it was predicted that:

H3: employee satisfaction had a mediating effect between HRM and counterproductive work behavior.

\section{The moderating role of $L M X$}

The exchange between the employee and his or her leader (supervisor) are referred to as leader-member exchange (LMX). The relationship is based on social exchange. According to Leader-member exchange theory, leaders develop different quality relationships with followers in their team. The higher the value of the exchange, the better the quality of the relationship between employee and leader (Martin et al., 2018) [6]. The quality of LMX can influence the attitude and behavior of employees and leaders. When leaders and employees establish good LMX, there is a kind of trust between employees and leaders. Employees are more convinced of their leaders and more motivated by human resource management activities, so as to reduce counterproductive work behavior and improve their positive behavior (Seo et al., 2017) [7]. Therefore, it was predicted that:

H4: LMX plays a moderating role between human resource management and counterproductive work behavior.

\section{METHODS}

\section{A. Sample}

The staff in new ventures were investigated, and they were asked to fill in an electronic questionnaire. Finally, 526 valid questionnaires were collected. 150 respondents were male, accounting for $28.5 \%$, others were female, accounting for 71.5\%. $6.8 \%$ had a master's degree, $54.8 \%$ had a bachelor's degree. $63.5 \%$ were younger than 30 years old. $54.4 \%$ were common staff, the others were managers. $22.8 \%$ were first-line managers, $18.3 \%$ were middle managers, $4.6 \%$ were top managers.

\section{B. Measures}

In order to improve the validity of scale measurement, this study uses back-translation technique in scale translation. Besides that, this study uses a variety of methods to reduce common method variance. For example, in this study, all items were mixed and randomly arranged. During the process of filling out the questionnaire, the respondent was not informed of the true purpose of the measurement. Meanwhile, the necessary reverse items were used in the questionnaire.

Human resource management in new ventures. It was measured by the scale including 23 items from Delery \& Doty (1996) [8], including internal career opportunities, training, results-oriented appraisals, employment security, participation, job descriptions, profit sharing. The items are such as "Individuals in this job receive bonuses based on the profit of the organization" and "Individuals in this job have clear career paths within the organization". Cronbach's $\alpha$ was 0.941.

Counterproductive work behavior. This variable was assessed by scale from Ng, Lam \& Feldman (2015) [9], which had four items. Cronbach's $\alpha$ ware 0.935 .

Employee satisfaction. This variable was assessed by the Minnesota Satisfaction Questionnaire (MSQ), which had twenty items scale. Items are such as "I am satisfied with the way the leader treats his subordinates". In this study, coefficient alpha was 0.860 .

Leader-member exchange (LMX). It was measured by the scale including 16 items from Wang, Niu \& Law (2004) [10]. Items are such as "I feel very happy in my contacts with leaders" and "The ability of my superior leaders has been widely recognized by everyone”. Cronbach's $\alpha$ was 0.786 .

\section{RESUlTS}

\section{A. CMV and discriminant validity}

In addition to prior control, this study conducted Harman's one-factor test to further control the impact of common method variance. All items were put together for factor analysis without rotation. The percentage of variance explained by the first factor was $43.674 \%$, which was less than $50 \%$ of the total variance. The result indicated that CMV did not pose a significant threat to the validity of results and conclusions.

This study used AMOS 17.0 to run CFA test to examine the discriminant validity of the research concept. The CFA results are detailed in Table I. HRM means human resource 
management. ES is employee satisfaction. LMX is a leader-member exchange, and CWB is counterproductive to work behavior. According to Table I, the four-factor model fits much better than any other models $\left(\chi^{2} / \mathrm{df}=2.247, \mathrm{GFI}=0.934\right.$, $\mathrm{NFI}=0.957, \mathrm{CFI}=0.906$, IFI=0.943, RMSEA=0.059). The results show that there is a clear distinction between the conceptions and the discriminant validity is good.

TABLE I. RESULT OF CFA $(\mathrm{N}=526)$

\begin{tabular}{|l|l|l|l|l|l|l|}
\hline \multicolumn{1}{|c|}{ Model } & $\chi 2$ /df & GFI & NFI & IFI & CFI & $\begin{array}{c}\text { RMSE } \\
\text { A }\end{array}$ \\
\hline $\begin{array}{l}\text { four-factor } \\
\text { model }\end{array}$ & 2.247 & 0.934 & 0.957 & 0.943 & 0.906 & 0.059 \\
\hline $\begin{array}{l}\text { three-facto } \\
\text { r model }\end{array}$ & 2.491 & 0.816 & 0.881 & 0.783 & 0.795 & 0.123 \\
\hline $\begin{array}{l}\text { two-factor } \\
\text { model }\end{array}$ & 2.696 & 0.604 & 0.693 & 0.695 & 0.697 & 0.167 \\
\hline $\begin{array}{l}\text { one-factor } \\
\text { model }\end{array}$ & 2.942 & 0.596 & 0.582 & 0.643 & 0.640 & 0.371 \\
\hline
\end{tabular}

Notes: four-factor model: HRM, LMX, ES, CWB three-factor model: HRM+ES, LMX, CWB two-factor model: HRM+ES+LMX, CWB one-factor model: HRM+ES+LMX+CWB

\section{B. Descriptive statistics}

The mean, standard deviation and correlation coefficients of the study conceptions are detailed in Table II. HRM in new ventures and counterproductive work behavior (CWB) were negatively correlated $(\mathrm{r}=-0.199, \mathrm{p}<0.05)$. HRM in new ventures and employee satisfaction (ES) had positively correlation $(\mathrm{r}=-0.132, \mathrm{p}<0.05)$. Employee satisfaction showed a significant correlation with counterproductive work behavior ( $\mathrm{r}=0.677, \mathrm{p}<0.01)$. In addition, leader-member exchange (LMX) and counterproductive work behavior were negatively correlated $(r=-0.207, \mathrm{p}<0.01)$.

TABLE II. MEANS, STANDARD DEVIATIONS AND CORRELATIONS $(\mathrm{N}=$ 526)

\begin{tabular}{|c|c|c|c|c|c|}
\hline Variables & Mean & SD & $\mathbf{1}$ & $\mathbf{2}$ & $\mathbf{3}$ \\
\hline 1. HRM & 3.73 & .660 & & & \\
\hline 2. CWB & 2.33 & 1.098 & $-0.199^{*}$ & & \\
\hline 3. ES & 3.74 & .736 & $0.626^{* * *}$ & $-0.132^{*}$ & \\
\hline 4. LMX & 3.71 & .745 & $0.417^{* * *}$ & $-0.207^{* *}$ & $0.395^{* * *}$ \\
\hline
\end{tabular}

Notes: ${ }^{*} \mathrm{p}<0.05,{ }^{* *} \mathrm{p}<0.01,{ }^{* * *} \mathrm{p}<0.001$.

\section{Hypothesis testing}

Main effects of human resource management in new ventures (HRM) on employee counterproductive work behavior. In these Hypotheses 1, it was predicted that HRM would negatively associate with counterproductive work behavior. According to Model 2 in Table III, the coefficients of HRM and counterproductive work behavior is significant and negative $(\beta=-0.247, \quad \mathrm{p}<0.01)$. Thus, Hypotheses 1 is supported.

Human resource management (HRM) on employee satisfaction (Hypothesis 2). In Hypotheses 2, it was predicted that HRM would positively associate with employee satisfaction. According to Model 1 in Table III, the coefficients of HRM on employee satisfaction is significant and positive $(\beta=0.602, p<0.01)$. Thus, Hypotheses 2 is supported.
The mediating effect of employee satisfaction. In Hypotheses 3, it was predicted that employee satisfaction would have mediating effect between HRM and employee counterproductive work behavior. According to Model 3, the coefficients of HRM on employee counterproductive work behavior is $-0.167(\mathrm{p}<0.01)$, which is smaller than that in Model 2. At the same time, the coefficients of employee satisfaction on counterproductive work behavior is -0.135 $(\mathrm{p}<0.01)$. Thus, Hypotheses 3 is supported.

Moderating effects of leader-member exchange (LMX). To test Hypotheses 4, the two-way interaction between HRM and LMX was entered into the regression analyses (see Model 5 in Table III). According to Model 5, the beta coefficient for the interaction term is statistically significant $(\beta=-0.09, \mathrm{p}<0.05)$. It shows a significant moderating effect of LMX on the relationship between HRM and counterproductive work behavior. Hypotheses 4 is supported.

TABLE III. HRM, EMPLOYEE SATISFACTION AND EMPLOYEE PERFORMANCE

\begin{tabular}{|l|c|c|c|c|c|}
\hline \multirow{2}{*}{ Variable } & ES & \multicolumn{4}{|c|}{ Counterproductive Work Behavior } \\
\cline { 2 - 6 } & Model 1 & Model 2 & Model 3 & Model 4 & Model 5 \\
\hline HRM & $0.602^{* *}$ & $-0.247^{* *}$ & $-0.167^{* *}$ & $-0.216^{* *}$ & $-0.213^{* *}$ \\
\hline ES & & & $-0.135^{* *}$ & & \\
\hline LMX & & & & $-0.102^{* *}$ & $-0.114^{* *}$ \\
\hline HRM $\times$ LMX & & & & & $-0.09^{*}$ \\
\hline $\mathrm{R}^{2}$ & 0.368 & 0.102 & 0.379 & 0.335 & 0.351 \\
\hline F & $17.973^{* *}$ & $3.191^{* *}$ & & $3.180^{* *}$ & $3.206^{* *}$ \\
\hline
\end{tabular}

Notes: $* \mathrm{p}<0.05 ; * * \mathrm{p}<0.01$

Employee Satisfaction (ES), leader-member exchange (LMX)

\section{CONCLUSION AND DISCUSSION}

\section{A. Theoretical implications}

The effects of Human Resource Management (HRM) in new ventures on employee counterproductive work behavior. This study confirms the negative relationship between HRM and counterproductive work behavior. $\mathrm{H} 1$ are supported. The better human resource management activities, the less counterproductive work behavior of employees. The conclusions of HRM in this study are consistent with those of previous studies. This study validates the value of human resource management in new ventures, and enriches the relevant research on counterproductive work behavior (Zhang et al., 2018) [11].

The mediating role of employee satisfaction. This study confirms the positive relationship between HRM and employee satisfaction (H2), and support the mediating effects of employee satisfaction between HRM and counterproductive work behavior (H3). When a new enterprise provides tangible or intangible incentives such as salary, training, development and participation for its employees through human resources management activities, employees face and accept these incentives, they will first feel satisfied. As a result, employees will show low level of counterproductive work behavior as a rewarding exchange behavior. This study enriches the relevant research evidence of employee satisfaction. 
The moderating role of leader-member exchange (LMX). The results support the moderating effects of the LMX between HRM and counterproductive work behavior. LMX reflects the work exchange relationship between employees and superiors. When LMX is better, employees have a higher degree of trust in their superiors. They are more willing to make positive attribution judgments for human resource management activities, and to make the positive exchange and reciprocity behavior. The results of the regression analysis confirmed Hypothesis 4, for employees who have better LMX, human resource management has a greater impact on counterproductive work behavior.

\section{B. Practical implications}

This study explores the impact mechanism of human resource management on employee counterproductive work behavior. The conclusions of this study have some suggestions for new ventures to reduce employee counterproductive work behavior.

Initially, new ventures should pay more attention to human resource management and effectively organize human resource management practice. Specifically, new ventures should organize extensive training for employees to improve their competence, assist employees in career planning and provide career development and promotion opportunities, perfect job description and update information in time, perfect the performance appraisal mechanism and establish a result-oriented and team-oriented appraisal system, rationally design the salary system of employees and improve the incentive function of salary. All these human resource management practices can effectively decline employees' counterproductive work behavior.

Secondly, this study shows that employee satisfaction plays a mediating role in human resource management and employee counterproductive work behavior. The higher employee satisfaction, the lower employee counterproductive work behavior. Therefore, new ventures should attach great importance to the level of employee satisfaction and take effective measures to improve employee satisfaction. Enterprises should provide a fair and competitive compensation system. Leaders provide the management of both kindness and authority for employees. Enterprises try their best to create a good working environment for employees and provide promotion and training mechanism. All of these methods help to improve employee satisfaction, and then to reduce employee counterproductive work behavior.

Finally, the relationship between employees and leaders is particularly important in new ventures. LMX affects the relationship between human resource management and employee counterproductive work behavior. Leaders should treat employees equally in their work so as to convince people. In the aspect of life, leaders can communicate with employees, so as to close the relationship with employees. Through these behaviors, high-quality LMX can be established, which should enhance employee loyalty and organizational commitment, promote the influence of human resource management and reduce counterproductive work behavior to a greater extent, and ultimately contribute to corporate effectiveness.

\section{REFERENCES}

[1] Marcus, O. A. Taylor, S. E. Hastings, A. Sturm, and O. Weigelt, "The structure of counterproductive work behavior: a review, a structural meta-analysis, and a primary study,” Journal of Management, vol. 42, pp. 203-233, January 2016

[2] J. Wang, Z. Zhang, W. N. Fan, "The research on the relationship among high-performance work system, psychological contract violation and counterproductive work behavior: A moderated mediation model," Journal of Industrial Engineering and Engineering Management, vol. 32, pp. 8-16, February 2018. ((In Chinese))

[3] J. Wang, Z. Zhang, M. Jia, "The research on the relationship between socially responsible human resource management and counterproductive work behavior : A moderated mediation model," Journal of Industrial Engineering and Engineering Management, vol. 33, pp. 19-27, April 2019. (In Chinese)

[4] M. Heffernan, T. Dundon, "Cross-level effects of high-performance work systems (HPWS) and employee well-being: the mediating effect of organizational justice," Human Resource Management Journal, vol. 26, pp. 211-231, April 2016.

[5] Y. Huang, Z. Ma, and Y. Meng, "High-performance work systems and employee engagement: empirical evidence from China," Asia Pacific Journal of Human Resources, vol. 56, pp. 341-359, July 2018.

[6] R. Martin, G. Thomas, A. Legood, S. D. Russo, "Leader-Member Exchange (LMX) Differentiation and Work Outcomes: Conceptual Clarification and Critical Review,” Journal of Organizational Behavior, vol. 39, pp. 151-168, January 2018.

[7] J. Seo, J. D. Nahrgang, M. Z. Carter, and P. W. Hom, "Not all differentiation is the same: examining the moderating effects of leader-member exchange (LMX) configurations,” Journal of Applied Psychology, vol. 103, pp. 478-495, December 2017.

[8] J. E. Delery, D. H. Doty, "Modes of theorizing in strategic human resource management: tests of universalistic, contingency, and configurational performance predictions," The Academy of Management Journal, vol. 39, pp. 802-835, August 1996.

[9] T. W. H. Ng, S. S. K. Lam, and D. C. Feldman, "Organizational citizenship behavior and counterproductive work behavior: Do males and females differ?” Journal of Vocational Behavior, vol. 93, pp. 11-32, December 2015.

[10] H. Wang, X. Y. Niu, K. S. Law, "Multi-dimensional Leader-member Exchange (LMX) and Its Impact on Task Performance and Contextual Performance of Employees,” Acta Psychologica Sinica, vol. 36, pp. 179-185, April 2004. (In Chinese)

[11] L. Zhang, Q. Huang, Y. Jiang, and C. Jiang, "Counterproductive work behavior: Research perspective, content and design," Advances in Psychological Science, vol. 26, pp. 306-318, February 2018. (In Chinese) 